\title{
Psychosocial Program for Primary School Student to Overcome School Refusal Behavior
}

\author{
Amira Awad Abouzid ${ }^{1}$, Galila Shawky El-Ganzory ${ }^{2}$ and Fathyea Said Sayed ${ }^{3}$ \\ (1)Specialist in Teaching Nursing Science in Imbaba Technical Health Institute, (2) Professor of \\ Psychiatric and Mental Health Nursing Faculty of Nursing Ain Shams University and (3) Lecture of \\ Psychiatric \& Mental Health Nursing Faculty of Nursing Benha University
}

\begin{abstract}
Background: School refusal behavior refers to a spectrum of problematic illegitimato absenteeism that includes youths who misschool or extended periods of time. School refusal behavior is the refusal to attend school due to emotional distress. School refusal differs from truancy in that children with school refusal feel anxiety or fear towards school. The term school refusal was coined to reflect that children have problems attending school for a variety of different reasons and these reasons might not be the expression of a true phobia such as separation or social anxiety. Aim: The aim of the present study was to develop the psychosocial program for school students to overcome school refusal behavior at basic school education. Design: A quasiexperimental design was used to achieve the aim of the study. Setting: This study was conducted at primary schools from Benha City, Qalubia Governorate, which is followed The Ministry of Education in Egypt. Subject: A systematic random method from six grade primary schools 69 students from Benha district on students with school refusal behavior. Tools: Three tools were used for data collection. Tool 1- Students Questionnaire includes socio-demographic data of students and their parents, medical and surgical history of parents. Tool 2- School refusal Assessment Scale. Tool 3- Spence children Anxiety Scale. Results: There was a highly statistically significant improvement in total score of school refusal behavior and total score of anxiety between pre and post implementation of the program. Conclusion: The study demonstrated that psychosocial program had a positive effect on overcoming school refusal behavior and anxiety among students at basic school education. Recommendations: A psychosocial program should be given for all school refusal students to enhance their social adjustment, reduce anxiety and overcome school refusal.
\end{abstract}

\section{Key words: Primary School, School refusal, anxiety, psychosocial program.}

\section{Introduction:}

School refusal behavior is a broad term that refers to a child-motivated refusal to attend school or difficulty remaining in class for an entire day. The behavior includes children and adolescents completely absent from school for an extensive period of time that skips classes or sections of a school day which are chronically tardy to school, who have severe morning misbehaviors in attempt to miss school and who attend school but with great difficulty. Repeated absence from school represents a significant deviation from a society's norm of behavior and socialization (Matsuura and Kishimoto, 2020).

Children and adolescents of all ages, boys and girls alike, can exhibit school refusal behavior. The most common age of onset is 10 to 13 years. School refusal is a psychosocial problem characterized by a 
child's or adolescent's difficulty attending school and, in many cases, substantial absence from school (Vaughn and Perron, 2017).

In the absence of treatment, most youth with school refusal continue to display problematic school attendance and emotional distress, leading to short- and long term adverse consequences. Nonattendance has been shown to negatively affect learning and achievement and to place youth at risk for early school dropout. The term of psychosocial refers to the dynamic relationship between psychological aspects of our experience (that is, our thoughts, emotions, and behaviors) and our wider social experience (that is, our relationships, family and community networks, social values, and cultural practices), where one influences the other (Krauss, et al 2017).

Assessment and management of school refusal require a collaborative approach that includes the family physician, school staff, parents, and a mental health professional. Because children often present with physical symptoms, evaluation by a physician is important to rule out any underlying medical problem (Minello and Blossfeld, 2016).

School nurses are often one of the first professionals in the school with the opportunity to interact with these children, recognize school refusal behavior and its debilitating impact, and positively intervene to assist these children to stay in school. School nurses can also play an important role in providing guidance to parents, making appropriate mental health referrals, and providing important information to school staff about school refusal behavior (Nand, 2017).

\section{Significance of the study}

School refusal is one of the main problems observed in almost all levels of education. Prevalence estimates for school refusal behavior vary from approximately 5$28 \%$ of school-age youths refuse school at some time in their lives. The short-term consequences of school refusal behavior include declining academic status, social alienation, and increased risk of legal trouble, family conflict, and severe disruption in a family's daily routine. The long-term consequences of school refusal behavior include school dropout and subsequent economic deprivation, occupational and marital problems, alcohol abuse and criminal behavior, and mental disorders (Uddin, 2016).

In Egypt students in rural areas are as likely to attend school as students in urban areas, where in urban areas $93 \%$ of students of primary school age attend school compared to $91 \%$ in rural area. No significant gender disparity is observed in either urban or rural area. Also, there are moderate regional disparities in primary school attendance. Primary net attendance is highest in the lower Egypt region 94\% (Egypt Demographic and Health Survey, 2008). So, the study aims to develop overcome school refusal behavior among children at basic school education psychosocial program for school students to attendance are lowest in the Frontier Governorates region $85 \%$. It is stated that in all regions, less than one -fifth of school age students don't attend school at the appropriate 


\section{Aim of the study:}

This study aimed to develop psychosocial program for school students to overcome school refusal behavior among children at basic school education.

\section{Subject and Method}

\section{Research Design:-}

- A quasi experimental design used to achieve the aim of the study.

\section{Setting:-}

This study conducted at primary schools from Benha City, Qalubia Governorate, which is following for The Ministry of Education.

A quasi-experimental design two groups control and study group was utilized in this study.

\section{Sample type:}

A convenient sample was selected.

\section{Sample size and technique:}

A convenience sample of 69 students were chosen from $6^{\text {th }}$ grade primary schools from Benha district on students with school refusal behavior. Data was collected over a period of six months since 2019 - 2020 from October 2019 to March.

\section{Tools of data collection}

Tool (1): Students Questionnaire was developed by the researcher consisted of:-

First part consists of personal data such as:-

A- Socio-demographic data of students included age, sex, number of family members living at home and child ranking in his family.

B- Socio-demographic data of students' parents included age, occupation and education.

Second part: Medical and surgical history of parents included chronic disease and history of surgical operation.
Tool (2): School Refusal Assessment Scale: This tool developed by (Kearney \& Silverman, 1995). It was translated by the researcher into Arabic language and tested for its content validity by group of five experts in the Psychiatric and Pediatric Nursing Staff, and modifications were carried out by correcting some items in language and scale modified from seven to three scale. School refusal assessment scale (SRAS) used to measure the conditions of school refusal consist of Child version (24 items) to assess the conditions of school refusal behavior included negative reinforcement of school refusal behavior and positive reinforcement of school refusal behavior.

Tool (3): Spence children Anxiety Scale:

This tool developed by (Spence and Ron, 1999). It was translated by the researcher into Arabic language and tested for its content validity by group of five experts in the Psychiatric and Pediatric Nursing Staff, and modifications were carried out by correcting some items and scales. Spence anxiety scale (SAS) consisted of Child version (45 items) designed to assess anxiety of children included separation anxiety, social phobia, obsessive compulsive, panic or agoraphobia, physical injury and generalized anxiety. It is 3 level scale for child, items are scored on 0-2 scale $0=$ never, $1=$ sometimes, and $2=$ always.

\section{Ethical considerations}

The aim of the study was explained to each students before applying the tools to gain their confidence and trust. Written consent was obtained from each students to participate in the study. The data were collected and treated confidentially. This study had no any harmful effect for nurses and don't touch religious, cultural \&ethical consideration.-Each student was informed about time throughout the study.Freedom to withdraw from participation in the study at any time. 


\section{Psychosocial Program for Primary School Student to Overcome School Refusal Behavior}

\section{Tool validity}

It was ascertained by a jury consisting of a group of 5 panel experts who were specialized in the Psychiatric and Pediatric Nursing Staff from Faculty of Nursing Ain Shams University ,professors in this field and experts from Faculty of Nursing Benha University. The tools proved to be valid. No modification was done.

\section{Reliability:}

Testing reliability of proposed tools was done by Cronbach Alpha test. It was calculated to assess the reliability that indicated that tool consisted of relatively homogenous items as indicated by the moderate to high reliability . The tools proved to be strongly reliable ( $\mathrm{r}$. $=0.82)$.

\section{Pilot study}

A pilot study was carried out on $10 \%$ of the study subjects. The purpose of the pilot study was to test the applicability, feasibility and clarity of the tools. In addition, it served to estimate the approximate time required for interviewing students as well as to find out any problems that might interfere with data collection. The sample of pilot study was included in the main sample as no modifications was done.

\section{Statistical analysis}

SPSS would be systematic. After implementation of program, each sheet was scored, the data were organized, categorized, tabulated, after that it was analyzed by using the statistical package for social science.

\section{Results:}

Table (1): Shows that, near to two thirds of the studied students $(63.8 \%)$ aged 12 years old with $\overline{(\mathbf{X}} \pm \mathbf{S D}$ of $11.63 \pm 0.484)$. Near to three quarters of the studied students $(68.1 \%)$ were males, and near to two thirds of the studied students $(63.8 \%)$ were repeaters.

Table (2) Describes that, half of the studied fathers $50.7 \%$ aged between 41 to less than 50 years old with $\overline{\mathbf{x}} \pm \mathbf{S D}$ of $42.36 \pm 8.32,43.5 \%$ of them had university education while near to half $(43.5 \%)$ of the studied mothers aged between 31 to less than 40 years old with $(\overline{\mathbf{x}} \pm \mathbf{S D}$ of $36.82 \pm$ $7.85),(42.0 \%)$ of them had secondary education.

Table (3) Shows that, there were highly statistically significant differences in all items related to the studied students' avoidance of school-related stimuli provoking negative affectivity between pre and post program $(\mathrm{P}<$ $0.001)$.

Table (4): Illustrates that, there were highly statistically significant differences in all items. Table (5): Reveals that, there were highly statistically significant relations between the studied students' total school refusal behavior score and their age, gender, class, number of family members, and living pre and post program $(\mathrm{P}<0.001)$.

Table (6): Indicates that, there was highly statistically significant positive correlation between the studied students' total anxiety and total school refusal behavior pre and post program $(\mathrm{P}<0.001)$.

Figure (1): represented that pre-program positive reinforcement of school refusal behavior score was $57.8 \%$ and become postprogram $42.2 \%$. Negative reinforcement of school refusal behavior score pre-program was $65.2 \%$ and become post-program (34.8\%)

Figure (2): revealed that there pre-program studied students score with anxiety were $78.3 \%$ and become post-program $29.0 \%$. 
Table (1): Distribution of the studied students according to their socio-demographic characteristics, $(n=69)$.

\begin{tabular}{|c|c|c|}
\hline Personal characteristics & No. & $\%$ \\
\hline \multicolumn{3}{|l|}{ Age (Years): } \\
\hline $11-$ & 25 & 36.2 \\
\hline $12-$ & 44 & 63.8 \\
\hline \multicolumn{3}{|l|}{$\overline{\mathbf{X}} \pm$ SD $11.63 \pm 0.484$} \\
\hline \multicolumn{3}{|l|}{ Gender: } \\
\hline Male & 47 & 68.1 \\
\hline Female & 22 & 31.9 \\
\hline \multicolumn{3}{|l|}{ Class: } \\
\hline Six grade & 25 & 36.2 \\
\hline Repeater six grade & 44 & 63.8 \\
\hline \multicolumn{3}{|l|}{ The number of family members: } \\
\hline $3<5$ & 30 & 43.5 \\
\hline $5<7$ & 36 & 52.2 \\
\hline $7<9$ & 3 & 4.3 \\
\hline \multicolumn{3}{|c|}{$\overline{\mathbf{X}} \pm \mathbf{S D} 4.68 \pm 1.19$} \\
\hline \multicolumn{3}{|l|}{ The child ranking: } \\
\hline $1^{\mathrm{st}}$ & 17 & 24.6 \\
\hline $2^{\text {nd }}$ & 16 & 23.2 \\
\hline $3^{\text {rd }}$ & 22 & 31.9 \\
\hline $4^{\text {th }}$ & 10 & 14.5 \\
\hline $5^{\text {th }}$ & 4 & 5.8 \\
\hline \multicolumn{3}{|l|}{ With whom the child lives: } \\
\hline Mother & 20 & 29.0 \\
\hline Father & 12 & 17.4 \\
\hline Family & 37 & 53.6 \\
\hline
\end{tabular}


Table (2): Frequency distribution of the studied students according to their parents' sociodemographic characteristics $(n=69)$.

\begin{tabular}{|c|c|c|c|c|}
\hline \multirow{2}{*}{$\begin{array}{l}\text { Socio-demographic } \\
\text { characteristics }\end{array}$} & \multicolumn{2}{|c|}{ Fathers } & \multicolumn{2}{|c|}{ Mothers } \\
\hline & No. & $\%$ & No. & $\%$ \\
\hline \multicolumn{5}{|l|}{ Age (Years): } \\
\hline $20 \leq 30$ & 4 & 5.9 & 10 & 14.5 \\
\hline $31 \leq 40$ & 21 & 30.4 & 30 & 43.5 \\
\hline $41 \leq 50$ & 35 & 50.7 & 25 & 36.2 \\
\hline \multirow[t]{2}{*}{$51 \leq 60$} & 9 & 13.0 & 4 & 5.8 \\
\hline & \multicolumn{2}{|c|}{$\overline{\mathbf{X}} \pm \mathbf{S D} 42.36 \pm 8.32$} & \multicolumn{2}{|c|}{$\overline{\mathbf{X}} \pm$ SD $36.82 \pm 7.85$} \\
\hline \multicolumn{5}{|l|}{ Educational level: } \\
\hline Don't read and write & 10 & 14.5 & 10 & 14.5 \\
\hline Primary education & 11 & 15.9 & 12 & 17.4 \\
\hline Secondary education & 18 & 26.1 & 29 & 42.0 \\
\hline University education & 30 & 43.5 & 18 & 26.1 \\
\hline \multicolumn{5}{|l|}{ Marital status: } \\
\hline Married & 37 & 53.6 & 37 & 53.6 \\
\hline Divorced & 22 & 31.9 & 22 & 31.9 \\
\hline Widowed & 10 & 14.5 & 10 & 14.5 \\
\hline \multicolumn{5}{|l|}{ Monthly income: } \\
\hline Enough & 31 & 44.9 & 29 & 42.0 \\
\hline Not enough & 38 & 55.1 & 40 & 57.9 \\
\hline \multicolumn{5}{|l|}{ Occupation: } \\
\hline Housewife(not work) & \multicolumn{2}{|l|}{34} & 49.3 & 56.5 \\
\hline Employee & \multicolumn{2}{|l|}{35} & $\begin{array}{l}50.7 \\
\end{array}$ & 43.5 \\
\hline \multicolumn{5}{|l|}{ Residence: } \\
\hline Urban & 25 & 36.2 & 25 & 36.2 \\
\hline Rural & 44 & 63.8 & 44 & 63.8 \\
\hline
\end{tabular}


Table (3): Frequency distribution of the studied students regarding to their negative of school refusal behavior pre and post psychosocial program, $(n=69)$.

\begin{tabular}{|c|c|c|c|c|c|c|}
\hline \multirow{2}{*}{$\begin{array}{l}\text { Negative reinforcement of } \\
\text { school refusal behavior }\end{array}$} & \multicolumn{2}{|c|}{ Pre program } & \multicolumn{2}{|c|}{ Post program } & \multicolumn{2}{|c|}{ Significance test } \\
\hline & No. & $\%$ & No. & $\%$ & $\chi^{2}$ & P-value \\
\hline \multicolumn{7}{|c|}{ A- Avoidance of school-related stimuli provoking negative affectivity. } \\
\hline \multicolumn{7}{|c|}{$\begin{array}{l}\text { 1- How often do the student have bad feelings about going to school because the } \\
\text { students are afraid of something related to school (e.g, tests, school bus, teacher, fire } \\
\text { alarm)? }\end{array}$} \\
\hline Always & 45 & 65.2 & 13 & 18.8 & \multirow{3}{*}{61.45} & \multirow{3}{*}{$0.001 * *$} \\
\hline Sometimes & 11 & 15.9 & 10 & 14.5 & & \\
\hline Never & 13 & 18.8 & 46 & 66.7 & & \\
\hline \multicolumn{7}{|c|}{$\begin{array}{l}\text { 2- How often do the student stay away from school because feel sad or depressed if } \\
\text { you go? }\end{array}$} \\
\hline Always & 42 & 60.9 & 6 & 8.7 & \multirow{3}{*}{54.29} & \multirow{3}{*}{$0.001 * *$} \\
\hline Sometimes & 21 & 30.4 & 14 & 20.3 & & \\
\hline Never & 6 & 8.7 & 49 & 71.0 & & \\
\hline \multicolumn{7}{|c|}{$\begin{array}{l}\text { 3- How often do the student feel worse at school (e.g, example, scared, nervous, or } \\
\text { sad) compared to how the student feel at home with friends? }\end{array}$} \\
\hline Always & 37 & 53.6 & 18 & 26.1 & \multirow{3}{*}{29.38} & \multirow{3}{*}{$0.001 * *$} \\
\hline Sometimes & 22 & 31.9 & 15 & 21.7 & & \\
\hline Never & 10 & 14.5 & 36 & 52.2 & & \\
\hline \multicolumn{7}{|c|}{$\begin{array}{l}\text { 4- How often do the student have bad feelings about school (e.g, scared, nervous, or } \\
\text { sad) when the student think about school on Saturday and Sunday? }\end{array}$} \\
\hline Always & 40 & 57.9 & 20 & 29.0 & \multirow{3}{*}{27.69} & \multirow{3}{*}{$0.001 * *$} \\
\hline Sometimes & 20 & 28.9 & 15 & 21.7 & & \\
\hline Never & 9 & 13.0 & 34 & 49.3 & & \\
\hline \multicolumn{7}{|c|}{$\begin{array}{l}\text { 5- If the student had less bad feelings (e.g, scared, nervous, sad) about school, would } \\
\text { it be easier for you to go to school? }\end{array}$} \\
\hline Always & 19 & 27.5 & 33 & 47.8 & \multirow{3}{*}{32.38} & \multirow{3}{*}{$0.001 * *$} \\
\hline Sometimes & 20 & 29.0 & 17 & 24.6 & & \\
\hline Never & 30 & 43.5 & 19 & 27.5 & & \\
\hline
\end{tabular}


Table (4): Frequency distribution of the studied students regarding to their positive reinforcement of school refusal behavior pre and post psychosocial program $(n=69)$.

\begin{tabular}{|c|c|c|c|c|c|c|}
\hline \multirow{2}{*}{$\begin{array}{l}\text { Positive reinforcement of } \\
\text { school refusal behavior }\end{array}$} & \multicolumn{2}{|c|}{ Pre program } & \multicolumn{2}{|c|}{ Post program } & \multicolumn{2}{|c|}{ Significance test } \\
\hline & No. & $\%$ & No. & $\%$ & $\chi^{2}$ & P-value \\
\hline \multicolumn{7}{|c|}{ 1- How often do you feel you would rather be with your parents than go to school? } \\
\hline Always & 40 & 57.9 & 22 & 31.9 & \multirow{3}{*}{65.50} & \multirow{3}{*}{$0.001 * *$} \\
\hline Sometimes & 17 & 24.6 & 12 & 17.4 & & \\
\hline Never & 12 & 17.4 & 35 & 50.7 & & \\
\hline \multicolumn{7}{|c|}{ 2- How much would you rather be with your family than go to school? } \\
\hline Always & 39 & 56.5 & 44 & 63.8 & \multirow{3}{*}{42.64} & \multirow{3}{*}{$0.001 * *$} \\
\hline Sometimes & 16 & 23.2 & 15 & 21.7 & & \\
\hline Never & 14 & 20.3 & 10 & 14.5 & & \\
\hline \multicolumn{7}{|c|}{ 3- How much would you rather be taught by your parents at home } \\
\hline Always & 41 & 59.4 & 28 & 40.6 & \multirow{3}{*}{20.36} & \multirow{3}{*}{$0.001 * *$} \\
\hline Sometimes & 11 & 15.9 & 10 & 14.5 & & \\
\hline Never & 17 & 24.6 & 31 & 44.9 & & \\
\hline \multicolumn{7}{|c|}{ 4- Would it be easier for you to go to school if your parents went with you? } \\
\hline Always & 25 & 36.2 & 33 & 47.8 & \multirow{3}{*}{27.16} & \multirow{3}{*}{$0.001 * *$} \\
\hline Sometimes & 20 & 29.0 & 24 & 34.8 & & \\
\hline Never & 24 & 34.8 & 12 & 17.4 & & \\
\hline \multicolumn{7}{|c|}{ 5- Would you like to be home with your parents more than other kids your age } \\
\hline Always & 35 & 50.7 & 22 & 31.9 & \multirow{3}{*}{35.97} & \multirow{3}{*}{$0.001 * *$} \\
\hline Sometimes & 22 & 31.9 & 16 & 23.2 & & \\
\hline Never & 12 & 17.4 & 31 & 44.9 & & \\
\hline \multicolumn{7}{|l|}{ Total } \\
\hline Always & 34 & 49.3 & 15 & 21.7 & \multirow{3}{*}{44.85} & \multirow{3}{*}{$0.001 * *$} \\
\hline Sometimes & 17 & 24.6 & 13 & 18.8 & & \\
\hline Never & 18 & 26.1 & 41 & 59.4 & & \\
\hline
\end{tabular}


Table (5): Relation between the studied students' total school refusal behavior score and their personal characteristics pre and post program

\begin{tabular}{|c|c|c|c|c|c|c|c|c|}
\hline \multirow{4}{*}{$\begin{array}{l}\text { Students' personal } \\
\text { characteristics }\end{array}$} & \multicolumn{8}{|c|}{ Total school refusal behavior score } \\
\hline & \multicolumn{4}{|c|}{ Pre program } & \multicolumn{4}{|c|}{ Post program } \\
\hline & \multicolumn{2}{|c|}{ Positive } & \multicolumn{2}{|c|}{ Negative } & \multicolumn{2}{|c|}{ Positive } & \multicolumn{2}{|c|}{ Negative } \\
\hline & No. & $\%$ & No. & $\%$ & No. & $\%$ & No. & $\%$ \\
\hline \multicolumn{9}{|l|}{ Age (Years): } \\
\hline 11 & 16 & 23.2 & 9 & 13.0 & 5 & 7.2 & 20 & 28.9 \\
\hline 12 & 36 & 52.2 & 8 & 11.6 & 14 & 20.3 & 30 & 43.6 \\
\hline Significance test & \multicolumn{2}{|c|}{$X^{2}=15.90$} & \multicolumn{2}{|c|}{ P-value $<0.001 * *$} & \multicolumn{2}{|c|}{$X^{2}=16.70$} & \multicolumn{2}{|c|}{ P-value $<0.001 * *$} \\
\hline \multicolumn{9}{|l|}{ Gender: } \\
\hline Male & 29 & 42.0 & 18 & 26.1 & 10 & 14.5 & 37 & 53.6 \\
\hline Female & 16 & 23.2 & 6 & 8.7 & 8 & 11.6 & 14 & 20.3 \\
\hline Significance test & \multicolumn{2}{|c|}{$X^{2}=16.56$} & \multicolumn{2}{|c|}{ P-value $<0.001 * *$} & \multicolumn{2}{|c|}{$X^{2}=19.10$} & \multicolumn{2}{|c|}{ P-value $<0.001 * *$} \\
\hline \multicolumn{9}{|l|}{ Class: } \\
\hline Six grade & 15 & 21.7 & 10 & 14.5 & 7 & 10.1 & 18 & 26.1 \\
\hline Repeater six grade & 35 & 50.7 & 9 & 13.0 & 12 & 17.4 & 32 & 46.4 \\
\hline Significance test & \multicolumn{2}{|c|}{$X^{2}=15.90$} & \multicolumn{2}{|c|}{ P-value $<0.001 * *$} & \multicolumn{2}{|c|}{$X^{2}=16.70$} & \multicolumn{2}{|c|}{ P-value $<0.001 * *$} \\
\hline \multicolumn{9}{|c|}{ The number of family members: } \\
\hline $3-<5$ & 20 & 28.9 & 10 & 14.5 & 9 & 13.0 & 21 & 30.4 \\
\hline $5-<7$ & 25 & 36.2 & 11 & 15.9 & 12 & 17.4 & 24 & 34.8 \\
\hline $7-<9$ & 1 & 1.4 & 2 & 2.9 & 0 & 0.0 & 3 & 4.8 \\
\hline Significance test & \multicolumn{2}{|c|}{$X^{2}=18.89$} & \multicolumn{2}{|c|}{ P-value $<0.001 * *$} & \multicolumn{2}{|c|}{$X^{2}=19.50$} & \multicolumn{2}{|c|}{$\begin{array}{l}\text { P-value }< \\
0.001 * *\end{array}$} \\
\hline
\end{tabular}

Table (3): Correlation between the studied students' total anxiety and total school refusal behavior pre and post program, $(n=69)$.

\begin{tabular}{|c|c|c|c|c|}
\hline \multirow[t]{3}{*}{ Variables } & \multicolumn{4}{|c|}{ Total anxiety } \\
\hline & \multicolumn{2}{|c|}{ Preprogram } & \multicolumn{2}{|c|}{ Preprogram } \\
\hline & $\mathbf{R}$ & P-value & $\mathbf{R}$ & P-value \\
\hline Total school refusal behavior & 0.671 & $0.001 * *$ & 0.824 & $0.001 * *$ \\
\hline
\end{tabular}




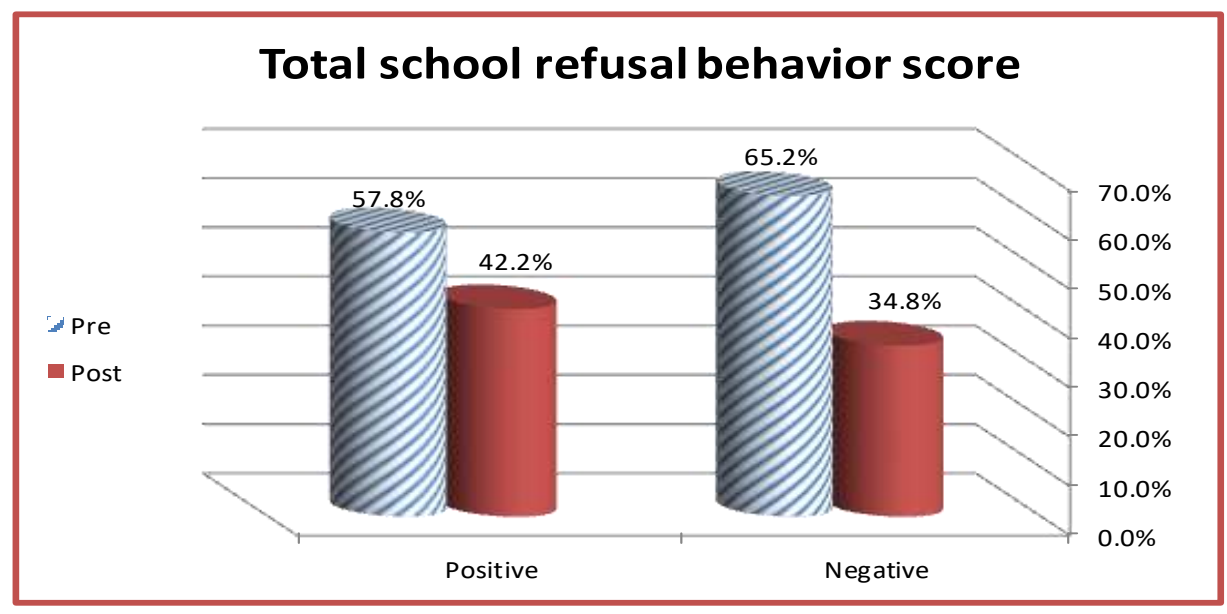

Figure (1): Percentage distribution of the studied students' regarding the total positive and negative reinforcement of school refusal behavior score pre and post program,

$$
(\mathbf{n}=69) \text {. }
$$

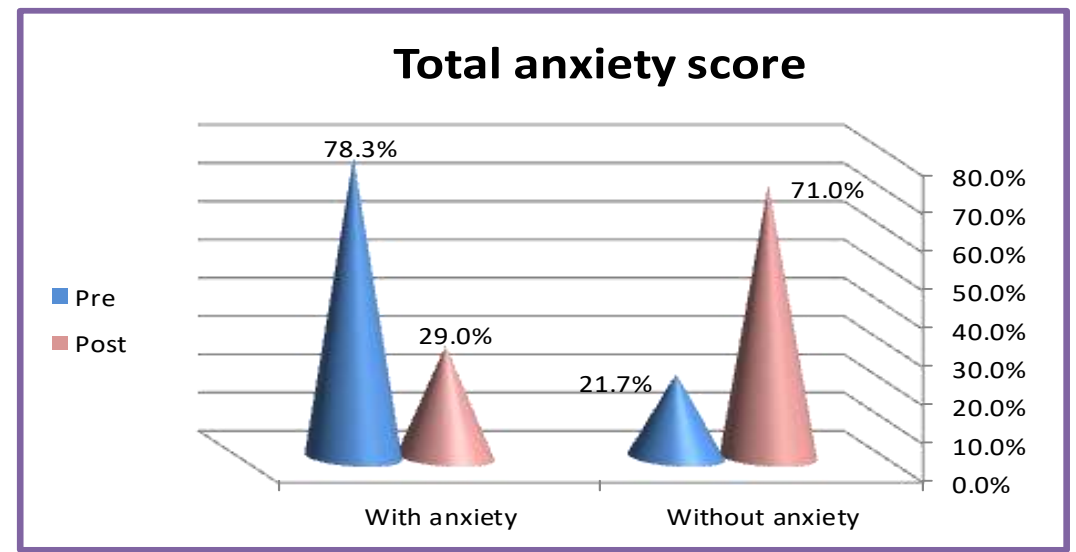

Figure (2): Percentage distribution of the studied students' total anxiety score pre and post psychosocial program, $(n=69)$.

\section{Discussion}

The present study revealed that, near to three quarters of the studied students their age ranged 12 years with mean age $11.63 \pm 0.484$ year. This finding could be due to transfer children to anther stage from primary school to secondary school. This result was in agreement with Kearney, (2018) \& Heyne et al., (2019), who found that, most of the studied students from the age group between 12 - 15 years old.

The present study revealed that, near to two thirds of the studied students were male. This result was in agreement with Zaff et al., (2017)
\& Yang and Ham, (2017), who found that, most of studied students have boys, This finding could be due to the over protection of male children than female children in our society.

On other hand this result was in disagreement with King, (2016) \& Orrenti et al., (2018), who reported that school refusal is at equal rates in both genders.

Moreover, the results of the current study showed that, near to two thirds of the studied students were six repeater grade. This result agreed with Gregory and Anita, (2014), who 
found that more than half of the studied students were repeaters.

The present study revealed that, more than half of the studied father age ranged from 41 to less than 50 years old with $\overline{\mathbf{x}} \pm \mathbf{S D}$ of $\mathbf{4 2 . 3 6} \pm \mathbf{8 . 3 2}$. However, near to half of the studied mothers aged between 31 to less than 40 years old with $\overline{\mathrm{X}} \pm \mathrm{SD}$ of $\mathbf{3 6 . 8 2} \pm \mathbf{7 . 8 5}$.

These result supported by Silove et al., (2015), who found that parents of school refusal children were in the age group from 35-45 years old. This may be due to the majority of the studied parents were educated, mother married at age 23 , father married at age 28 after found working, having first child at 25 years old and child go to school age six, and this mean that the parent ranged between 35- 45 years old.

As regards, the educational level the current study showed that near to half of mother of school refusal children had secondary education, on another hand near to half of fathers of school refusal children had university education, This results were in accordance with Kathrine et al., (2017), who found that, the majority of parents of school refusal children had high education. This may be due to the importance of education in these years so both parents were secondary and university education. Moreover, results of the current study showed that marital status of the studied parents more than half of studied parents of school refuser with stable marital status.

Regarding avoidance of school -related stimuli provoking negative affectivity among studied students pre and post program implementation, the current study results indicated that there was a highly statistical significant improvement in the mean score of all items of negative reinforcement of school refusal behavior post psychosocial nursing program than pre intervention program.
The present study clarified that more than half of school refusal students had bad feelings about going to school, feel sad or depressed if going to school, felt worse at school and afraid of something related to school. This finding also agreed with Leonie and Marija, (2017), who stated that more than two thirds of school refusers have an avoidance of school-related stimuli provoking negative affectivity.

In addition, this result can be explained that, the psychosocial program helped the students to identified conditions or situations that affect negative avoidance of school and to analyzed thoughts and feelings about them, as being rational or irrational. Then, replace these with accurate, rational, constructive thoughts. In addition, it helped the students to change feelings about school. This leads to experiencing positive reinforcement of school refusal behavior.

This analysis supported by (American Psychiatric Association, 2018) who reported that most of the treatments for school refusal today depend on changing negative feelings. The researcher's point of view was that before program implementation the students had bad feelings about schools that could be due to hear bad situation from siblings about school after implementation program change bad feeling to good feeling by good situation about school. According to previous studies, this profile has been considered as the maladaptive and, therefore, requires more attention Gonzálvez et al., (2018). Students who belong to this profile base their refusal to attend school on feelings of negative affectivity, social aversion and anxious symptoms. The appearance of these negative emotions inevitably impacts on the establishment of social relationships, causing deficiencies in the development of an adaptive social functioning Brouwer and Heyne, (2019). In this line, several studies suggested that the establishment of good social 
relationships with friends and classmates can prevent the appearance of school refusal behavior Gonzálvez et al., (2019) \& Shilvock, (2015). On the contrary, as expected, the group called Non-school refusers, characterized by low scores in the factors of the school refusal assessment and achieved the highest scores in social functioning.

Post program the present study revealed that, there were highly statistically significant differences in all items related to the studied students' desire to get attention from others between pre and post program $(\mathrm{P}<0.001)$. The school refuser student scores become better in social functioning. The researcher attributed the results of the study to the effectiveness of the psychosocial intervention program session that increased good social relationships with friends and classmates can reduce the appearance of school refusal behavior.

The researcher attributed the results of the study could be due to treatments often include behavioral interventions (e.g., relaxation training) and cognitive interventions (e.g., developing and using anxiety-reducing thoughts) in order to help youth with school refusal manage their anxiety and thus be better placed to increase their school attendance. One explanation for the lack of effects on anxiety might be found in the timing of the assessment of outcome measures

The present study shows relation between the studied students' total school refusal behavior score and their personal characteristics pre and post psychosocial program. Some demographical variables relation to school refusal were also investigated. The results indicated that gender had highly statistically significant relations between gender and school refusal behavior. There are inconsistent study results in the literature. In some studies
Filippello et al., (2019), was reported that school refusal is at equal rates in both genders; however, in another study agree with my result Kearney and Graczyk, (2020), higher rates are shown for men. Based on the results, it can be stated that the roots of school refusal behaviors have more specific features and cannot be completely explained through gender stereotypes.

The behavior of school refusal is linked to other disorders grounded in anxiety or phobias. The current study indicates that, there was highly statistically significant positive correlation between the studied students' total anxiety and total school refusal behavior pre and post program $(\mathrm{P}<0.001)$.Some relationships established by (Kearney and Silverman, 2018) between the function of school refusal measured by SRAS and some types of anxiety are confirmed: 'attentive-getting behaviour' is linked to separation anxiety. 'avoidance of stimuli' is linked to state-trait anxiety

School refusal may interrupt the development of positive self-perception and healthy social relations of the refusers thus, causing withdrawal from friends, rejection by peers, and academic failure (Tekin et al., 2018).

\section{Conclusion}

There were highly statistically significant relations between the studied students' total school refusal behavior score and their age, gender, class, number of family members. There were highly statistically significant relations between the studied students' total anxiety score and their age, gender, class, number of family members, and living post program. There was highly statistically significant positive correlation between the studied students' total anxiety and total school refusal behavior pre and post program $(\mathrm{P}<0.001)$. 


\section{Recommendations}

- Develop a screening and assessment tool for school refusal for school and psychiatric settings.

- Psychiatric nurses, Community health nurse, Pediatric nurse and school health nurse should offer counseling services for parent and their children regarding school refusal behavior.

- Psychological counseling should be integrated as a part of routine intervention for students' school refusal behavior to enhance their self-esteem.

- Reassess the relevance of all psychosocial programs which should reflect students current and longer term social and economic interests.

\section{References}

Bagnell, A., (2015). Anxiety and separation disorders. Pediatric Review, 32,(10): Pp 440446.behavioral therapy for adolescent school refusal: Rationale and

Berg , M., (2016). Is urban poverty the cause for absenteeism in schools? Malaymailonline. Retrieved from

https://www.themalaymailonline.com

Christian, F. \& Kyla, A. (2019). When Children and Adolescents Do Not Go to School: Terminology, Technology, and Trends. Pediatric Anxiety Disorders, Pp439460.

Filippello, P., Buzzai, C., Costa, S., \& Sorrenti, L. (2019). School Refusal and Absenteeism: Perception of Teacher Behaviors, Psychological Basic Needs, and Academic Achievement. Original research article. doi.org/10.3389/fpsyg.2019.01471.
Gonzálvez, C., Inglés, C., FernándezSogorb, A., Sanmartín, R., Vicent, M., \& García-Fernández, J., (2019). Profiles derived from the School Refusal Assessment Scale-Revised and its relationship to anxiety. Educational Psychology, 40(3): Pp 1-14.

Gregory, I., \& Anita, P. (2014). Extended school non-attenders' views: developing best practice. Educational Psychology in Practice theory, research and practice in educational psychology, $30 \quad$ (1): $\quad$ Pp 37-50. https://doi.org/10.1080/02667363.2013.86948 9.

Heyne, D., Strömbeck, J., Alanko, K., Bergström, M., \& Ulriksen, R. (2019). A Scoping Review of Constructs Measured Following Intervention for School Refusal: Are We Measuring Up? Journal of the American Academy of Child \& Adolescent Psychiatry, 41, Pp 687-695.

Kathrine, E., Torske, T., Gjevik, E., Nærland, T., Pripp, H., \& Diseth, T. (2017). Individual characteristics of students with autism spectrum disorders and school refusal behavior. Review Sage Journal, 23(2): Pp 413-423

Kearney, C. (2018). School Absenteeism and School Refusal Behavior in Youth: A Contemporary Review. Clinical psychology Review, (28): Pp 451- 471. Psychological Association.

Kearney, C. \& Graczyk, P. (2020). A Multidimensional, Multi-tiered System of Supports Model to Promote School Attendance and Address School Absenteeism. Clinical Child and Family Psychology Review, (23) : Pp316-337.

King, N., \& Bernstein, G., (2016). School refusal in children adolescents: A review of the past 10 years. J. Am. Acad. Child Adolescent Psychiatry, 40, Pp197-205. 
Leonie J. \& Marija M. (2017). Functional Assessment of School Attendance Problems: An Adapted Version of the School Refusal AssessmentScale-Revised. Journal of Emotional and Behavioral Disorders, 25(3).

Maynard, B., Heyene, D., Brendel, K.,\& Bulanda, J. (2018). Treatment for School Refusal Among Children and Adolescents: A Systematic Review and Meta-Analysis. Research on Social Work Practice, 28(1) https://doi.org/10.1177/1049731515598619.

Moonie, S., Sterling, D., Figgs, L., \& Castro, M., (2015). Asthma status and severity affects missed school days. Journal of School Health, 76: Pp 18-24.

Nayak, A., Sangoi, B., \& Nachane, H. (2018). School Refusal Behavior in Indian Children: Analysis of Clinical Profile, Psychopathology and Development of a BestFit Risk Assessment Model. The Indian Journal of Pediatrics, (85): Pp1073-1078.

Nursalim,M., Hidayah,N., Atmoko,A., \& Radjah, C. (2018). pattern of school refusal behavior on students; background, triggers, family profile and treatment. European Journal of Education Studies, 4(9).

Ogundele, M. (2018). Behavioral and emotional disorders in childhood: A brief overview for pediatricians. World $\mathrm{J}$ Clin Pediatr, 7(1): Pp 9-26.

Orrenti, L., Filippello, P., Buzzai, C., Buttò, C., and Costa, S. (2018). Learned helplessness and mastery orientation: the contribution of personality traits and academic beliefs. Nord. Psychol, (70) : Pp 71-84. doi: 10.1080/19012276.2017.1339625.

Tekin, I., \& Erden, S. (2018). The predictor of school refusal: Depression, anxiety, cognitive distortion and attachment.
Journal of Human Science, 15(3): Pp15191529.

Vaghn, M., Niemiec, C. , \& Soenens, B. (2017). "The development of the five mini-theories of self-determination theory: an historical overview, emerging trends, and future directions," in Advances in Motivation and Achievement v. (16)

Yang, K., \& Ham, S. (2017). Truancy as systemic discrimination: anti-discrimination legislation and its effect on school attendance among immigrant children. Soc. Sci. J; 1(54): Pp. 216-226.

Zaff, J., Donlan, A., Gunning, A., Anderson, S., McDermott, E., \& Sedaca, M. (2017). Factors that promote high school graduation: a review of the literature. Psychol. Rev. (29): Pp.447-476. 


\section{برنامج نفسي اجتماعي لطلاب المرحلة الابتدائية للتظلب على سلوك الرفض من المدرسة}

\section{أميرة عوض أبوزيد - جليلة شوقي الجنزوري - فتحية سعيد سيد}

يشير سلوك رفض الددرسة إلى جانب من جو انب التغيب عن المدرسه لذا هدفت هذه الدراسة هو تطوير

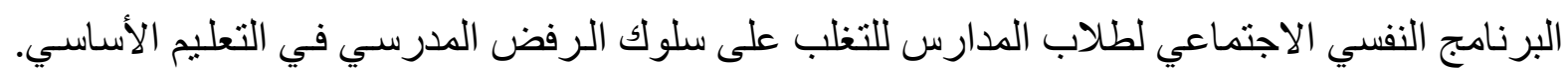
حيث تم استخدام تصميم شبه تجريبي لتحقيق هدف الدر اسـة. وأجريت هذه الدر استة بالمدارس الابتدائية

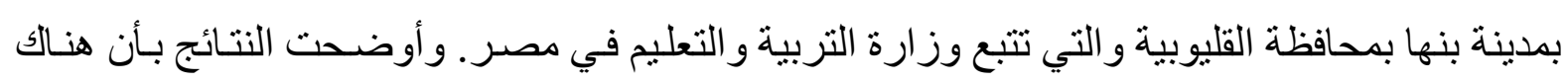

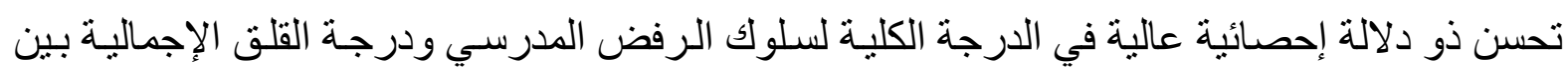

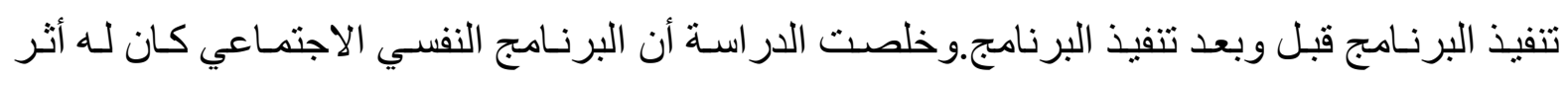

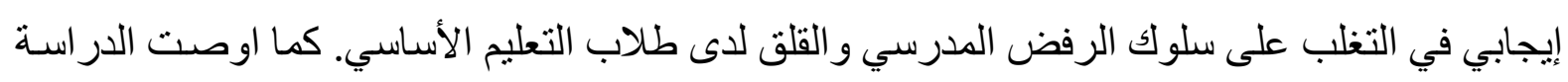

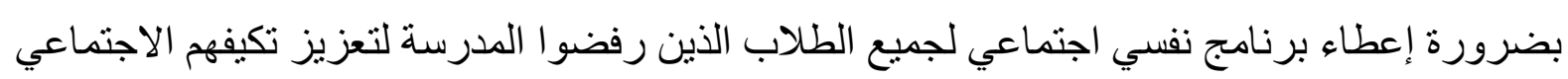
وتقليل القلق و التغلب على الرفض الدرسي. 